\title{
COMO MÉDICOS SE TORNARAM DEUSES: REFLEXÕES ACERCA DO PODER MÉDICO NA ATUALIDADE
}

\author{
HOW PHYSICIANS BECOME GODS: REFLECTIONS ON MEDICAL POWER TODAY \\ COMO LOS MÉDICOS SE CONVIERTEN EN DIOSES: REFLEXIONES SOBRE EL PODER MÉDICO HOY
}

\author{
Andrea Cristina Lovato Ribeiro* \\ Alcindo Antônio Ferla*
}

\begin{abstract}
RESUMO
A concepção atual de saúde refere-se a um conceito mais amplo de condiçôes do que a ausência de doença. Esse conceito destaca a importância de um cuidado em saúde que possa levar em consideração não apenas os sintomas apresentados pelas pessoas. Porém o modelo de atenção à saúde vigente é um modelo centrado na figura do médico, como representante de uma lógica de conhecimentos e práticas bem específica, na doença como foco das intervenções e no uso excessivo de equipamentos tecnológicos e medicamentos. Este artigo ensaístico propõe reflexões acerca de como o médico passou a ocupar papel central na Modernidade e ganhou legitimidade para decidir sobre o valor das vidas humanas. Primeiramente serão feitas considerações sobre o nascimento da biopolítica, com base nas contribuiçōes de Michel Foucault, seguindo com uma aproximação teórica entre medicina, vida nua e poder soberano, inspirando-se nas reflexōes propostas por Giorgio Agamben. Por fim, serão apresentadas considerações sobre a medicalização da vida, baseando-se nas contribuições de João Biehl. A reflexão, articulando diferentes campos do conhecimento, sobre os papéis dos profissionais da medicina e das demais profissōes da saúde busca provocar o pensamento para possibilidades de atenção integral e um cuidado em saúde mais compatível com a vida encarnada das pessoas no interior dos serviços de saúde.
\end{abstract}

Palavras-chave: Cuidado em saúde. Poder médico. Biopolítica. Vida nua. Medicalização da vida.

\footnotetext{
Texto recebido em 5 de maio de 2013 e aprovado para publicação em 16 de outubro de 2014.

Mestra em psicologia Social e Clínica; psicóloga. Atua em projetos de educação permanente em saúde dos profissionais do SUS, junto ao Instituto Communitas para o Desenvolvimento Humano e Tecnológico, Ministério da Saúde, Organização PanAmericana da Saúde e Fundação Oswaldo Cruz. Endereço: Rua Os 18 do Forte, 1092, sala 1004 - Bairro Exposição, Caxias do Sul-RS, Brasil. CEP: 95020-471. E-mail: andrealovattoribeiro@gmail.com.

** Doutor em Educação; professor adjunto da Universidade Federal do Rio Grande do Sul (UFRGS), atuando no Bacharelado e no Mestrado em Saúde Coletiva; médico; professor colaborador no Programa de Pós-Graduação em Psicologia da UFPA; coordenador-geral dos projetos Rede Governo Colaborativo em Saúde e OTICS. Endereço: Rede Governo Colaborativo em Saúde, Avenida João Pessoa, 155, sala 301 - Centro Histórico, Porto Alegre-RS, Brasil. CEP: 90040-000.

E-mail: ferlaalcindo@gmail.com.
} 


\begin{abstract}
The current concept of health refers to a broader concept of the conditions rather than the absence of disease. This concept highlights the importance of health care that can take into account not just the symptoms presented by people. In spite of this, the current health care model is based on the doctor figure, as representative of a logic of knowledge and specific practices, on the disease as focus of interventions and on the overuse of drugs. This paper offers reflections on how the doctor came to occupy a central role in modern times and won legitimacy to decide about the value of human lives. Firstly, considerations about the birth of biopolitics derived from the contributions of Michel Foucault, leading to a theoretical approach between medicine, bare life and sovereign power, from the reflections proposed by Giorgio Agamben, will be presented. Finally, considerations on the medicalization of life will be given, from the contributions of John Biehl. The reflection, linking different fields of knowledge, about the roles of professionals in medicine and other health professions, seeks to provoke insight for comprehensive care and a health care more compatible with the incarnate life of people within the health services.
\end{abstract}

Keywords: Health care. Medical power. Biopolitics. Bare life. Medicalization of life.

\title{
RESUMEN
}

La concepción actual de salud se refiere a un concepto más amplio de condiciones que la ausencia de enfermedad. Este concepto destaca la importancia del cuidado de la salud que puede tener en cuenta no sólo los síntomas presentados por las personas. Sin embargo, el modelo de atención a la salud vigente es un modelo basado en la figura del médico como representante de la lógica de los conocimientos y prácticas bien específicas, en la enfermedad como foco de las intervenciones y en el uso excesivo de medicamentos. Este artículo propone algunas reflexiones sobre cómo el médico llegó a ocupar un papel central en los tiempos modernos y ganó legitimidad para decidir sobre el valor de la vida humana. Inicialmente serán hechas consideraciones sobre el nacimiento de la biopolítica a partir de las contribuciones de Michel Foucault, para seguir con un enfoque teórico entre medicina, la vida desnuda y el poder soberano, a partir de las reflexiones propuestas por Giorgio Agamben. Para terminar, serán presentadas consideraciones sobre la medicalización de la vida, a partir de las contribuciones de John Biehl. La reflexión, que une diferentes campos del conocimiento, sobre el papel de los profesionales de la medicina y otras profesiones de la salud, busca provocar el pensamiento a posibilidades de atención integral y un cuidado en salud más compatible con la vida encarnada de las personas dentro de los servicios de salud.

Palabras clave: Cuidado de la salud. Poder médico. Biopolítica. Vida desnuda. Medicalización de la vida. 


\section{INTRODUÇÃO}

A concepção atual de saúde se refere a um conceito muito mais amplo de condições do que a simples ausência de doença. É corrente, e reiterado pela Organização Mundial de Saúde (OMS), que a saúde pode ser entendida como um estado de completo bem-estar físico, mental e social. Apesar do inevitável questionamento sobre a possibilidade real de um bem-estar completo em todos esses níveis, esse conceito destaca a importância de um cuidado em saúde que possa levar em consideração não apenas os sintomas apresentados pelas pessoas. Para atender às necessidades de saúde das pessoas, que vão muito além do tratamento dos sintomas apresentados em decorrência da doença suposta, característica do modelo biomédico, faz-se necessária uma reestruturação do modelo assistencial. Passa-se a focar então em uma atenção integral em saúde. A integralidade em saúde é o resultado de um arranjo tecnoassistencial que se apresenta como um desafio em serviços nos quais estão presentes lógicas médicocentradas e procedimento-centradas (Merhy, 2002). Sobre a integralidade, Ferla (2009) afirma:

\footnotetext{
A integralidade implica na inserção do indivíduo em uma rede de serviços capaz de responder às necessidades, que se ampliam enormemente da dimensão biológica (na qual é centrada a prática hegemônica), mas que, minimamente, deve ser capaz de oferecer ações de promoção e proteção da saúde, integradas às açóes assistenciais necessárias à demanda singular de cada usuário (p. 28).
}

Para Merhy e Franco (2003), a mudança do modelo tecnoassistencial depende principalmente da produção de saúde que acontece na micropolítica da organização do trabalho, no âmbito das relações, nos vínculos entre os diferentes atores. Para garantir que todas as necessidades de saúde sejam atendidas, o modelo assistencial deve disponibilizar os recursos tecnológicos e conhecimentos específicos dos diversos profissionais da área da saúde, mas, mesmo assim, o cuidado deve ter em seu núcleo o "trabalho vivo". De acordo com Merhy e Franco (2003), o trabalho vivo refere-se ao trabalho em ato, campo de tecnologias relacionais, e deve ocupar lugar central no cuidado. O trabalho morto se refere ao núcleo tecnológico, em que não há mais atos criativos e inventivos.

Em um modelo de cuidado em saúde que busque a integralidade, e um cuidado cujo ponto central é o trabalho vivo, ou o campo do vínculo e das relações, a interdisciplinaridade é considerada fundamental, tanto para compreender a doença e a produção de saúde como para embasar açóes de cuidado no interior dos serviços. Para que a compreensão dos sujeitos de forma integral aconteça, são 
claros os limites de um único campo de saber (como o "saber médico" que embasa as práticas profissionais da saúde dos diferentes profissionais e, nuclearmente, a centralidade da atuação do profissional médico, por exemplo) e, mesmo, das agregações estanques dos diferentes núcleos de saber profissional.

Dada a complexidade do campo da saúde, Spink (2010), em texto recente, com sua experiência de muitos anos no ensino e pesquisa na área da Psicologia no contexto da saúde, afirma que os saberes necessários para um cuidado em saúde devem se estender para além dos diferentes campos da própria área. Segundo a autora, devido à complexidade do campo, os saberes teóricos e técnicos já não são suficientes:

A prática no contexto da saúde vai além da mera aplicação de técnicas baseadas em perspectivas teóricas. Embora necessárias, as técnicas devem ser adaptáveis e flexíveis para conseguirem ser capazes de lidar com os aspectos multidimensionais do campo da saúde (Spink, 2010, p. 47).

De acordo com Spink (2010), é necessário levar em consideração a formação ampliada ou a erudição. A autora relata que a erudição, nesse contexto, deve considerar os conhecimentos advindos da Antropologia, Medicina, Política, Sociologia, Administração e da própria Psicologia Social. Fala-se, aqui, não apenas da agregação, mas da combinação de saberes, ou seja, em composições híbridas que permitam compreensões ampliadas, capazes de ações de maior efetividade.

A integralidade em saúde é uma das principais diretrizes do Sistema Único de Saúde (SUS) e, com base nessa diretriz, o governo brasileiro instituiu diversos programas para o cuidado em saúde de sua população, entre eles a Estratégia Saúde da Família, que privilegia o trabalho em uma equipe de saúde, composta por diversos profissionais, nos saberes produzidos sobre e com base na dimensão biológica das doenças. Porém o modelo de atenção à saúde ainda vigente é centrado na figura do médico, como "portador" de um conhecimento tornado legítimo e predominante, na doença como foco das intervenções, no consumo de procedimentos de alta tecnologia e no uso excessivo de medicamentos. Apesar de esse modelo estar sendo questionado, existem muitos desafios para que mudanças reais nos serviços aconteçam, especialmente no que diz respeito à formação profissional. Além disso, percebe-se que mudanças estruturais (por exemplo, estratégias como a Saúde da Família) não garantem uma modificação na forma como os serviços são prestados e, em particular, nos modos como o trabalho se organiza no seu interior (Franco \& Merhy, 2007). 
Com base nisso, mostra-se inquietante como a Medicina, ao mesmo tempo campo profissional e campo de saberes, passou a ocupar papel central na Modernidade e como ganhou legitimidade para ocupar papel de protagonista do que diz respeito à saúde das pessoas e sobre o valor das vidas humanas. É importante entendermos então como esse processo aconteceu e pensarmos novas lógicas de organizar o cuidado. Nesse ensaio teórico, inicialmente serão feitas considerações sobre o nascimento da biopolítica, com base nas contribuições de Michel Foucault. Em seguida, será apresentada a relação entre "medicina" e a "vida nua", tal como proposta por Giorgio Agamben. Por fim, serão expostas considerações sobre a medicalização da vida e sobre como processos médicos afetam o curso da vida das pessoas, especialmente em contextos urbanos pobres, com base nas contribuições de João Biehl.

\section{A BIOPOLÍTICA E O CONTROLE DA POPULAÇÃO}

Michel Foucault (1999) nos mostra que, a partir do século XIX, a vida passa a ser alvo de controle pelo Estado:

Um dos fenômenos fundamentais do século XIX foi, é o que se poderia denominar a assunção da vida pelo poder: se vocês preferirem, uma tomada de poder sobre o homem enquanto ser vivo, uma estatização do biológico ou, pelo menos, uma certa inclinação que conduz ao que se poderia chamar de estatização do biológico (pp. 285-286).

Para a compreensão de como essa tomada de poder sobre o homem aconteceu, Foucault (1999) reflete sobre a teoria da soberania. Uma das características principais da soberania é o direito do soberano de fazer morrer e deixar viver: "O direito de vida e de morte só se exerce de uma forma desequilibrada, e sempre do lado da morte. O efeito do poder soberano sobre a vida só se exerce a partir do momento em que o soberano pode matar" (Foucault, 1999, p. 286). A partir do século XIX, surge um novo direito, ou um novo poder, que provoca uma grande transformação no direito político: o poder de "fazer" viver e "deixar" morrer, característica da biopolítica. Esse novo direito não apaga o primeiro, mas o transforma, e essa mudança não acontece rapidamente, mas é um processo (Foucault, 1999).

Para Foucault (1999), mostra-se fundamental o entendimento dos mecanismos, das técnicas e das tecnologias de poder utilizadas e como estas transformaram-se no decorrer do tempo. O autor nos mostra como essas tecnologias passaram de um foco no corpo dos indivíduos para as populaçóes. A partir do final do século XVII e primeira metade do século XVIII, surgem novas 
técnicas de poder centradas nos corpos individuais, o que Foucault denomina "tecnologia disciplinar do trabalho":

Eram todos aqueles procedimentos pelos quais se assegurava a distribuição espacial dos corpos individuais (sua separação, seu alinhamento, sua colocação em série e em vigilância) e a organização, em torno desses corpos individuais, de todo um campo de visibilidade. Eram também as técnicas pelas quais se incumbiam desses corpos, tentavam aumentarlhes a força útil através do exercício, do treinamento, etc. Eram igualmente técnicas de racionalização e de economia estrita de um poder que devia se exercer, da maneira menos onerosa possível, mediante todo um sistema de vigilância, de hierarquias, de inspeções, de escriturações, de relatórios (Foucault, 1999, p. 288).

A partir da metade do século XVIII, outra técnica começa a aparecer, desta vez não disciplinar e que não tem como foco os corpos individuais. Essa nova técnica não exclui a primeira, mas a integra, modificando-a em parte, e a tem como precondição de existência. O foco desta vez é o homem como ser vivo, o homem como espécie e não exclui as técnicas disciplinares focadas no homemcorpo, pois estão em níveis diferentes, em escalas diferentes (Foucault, 1999). Foucault (1999) nos mostra, de maneira clara, a diferença entre essas técnicas disciplinares, a que tem como foco o homem-corpo e a que tem como foco o homem como ser vivo:

A disciplina tenta reger a multiplicidade dos homens na medida em que essa multiplicidade pode e deve redundar em corpos individuais que devem ser vigiados, treinados, utilizados, eventualmente punidos. E, depois, a nova tecnologia que se instala se dirige a multiplicidade dos homens, não na medida em que eles se resumem em corpos, mas na medida em que ela forma, ao contrário, uma massa global, afetada por processos de conjunto que são próprios da vida, que são processos como o nascimento, a morte, a produção, a doença, etc. (Foucault, 1999, p. 289).

De acordo com Foucault (1999), são duas tomadas de poder. A primeira sobre o corpo, que se caracteriza por ser individualizante; e uma segunda tomada de poder, massificante, sobre o homem-espécie. Surge, com esta segunda tomada de poder, uma "biopolítica" da espécie humana. Esse biopoder tem como primeiros alvos de controle os nascimentos, as taxas de mortalidade, as taxas de reprodução, etc. De um modo geral, o foco são os dados sobre as populações, que geram as primeiras demografias. Esses dados passam a ser identificados e, com base nisso, são propostas intervenções. A Medicina passa então a ter uma nova função: 
São esses fenômenos que se começam a levar em conta no final do século XVIII e que trazem a introdução de uma medicina que vai ter, agora, a função maior da higiene pública, com organismos de coordenação dos tratamentos médicos, de centralização da informação, de normalização do saber, e que adquire também o aspecto de campanha de aprendizado da higiene e de medicalização da população. Portanto, problemas da reprodução, da natalidade, problema da morbidade também (Foucault, 1999, p. 291).

Além da natalidade e da morbidade, Foucault (1999) enumera como outras áreas principais de intervenção da biopolítica, as incapacidades biológicas diversas e os efeitos do meio (meio geográfico, climático, hidrográfico).

Para Foucault (1999), existem três pontos importantes para o entendimento da biopolítica:

a) o surgimento de um novo elemento importante como foco do poder, a população, e não mais os indivíduos ou a sociedade. É sobre a população que essa nova técnica de poder se dirige;

b) a natureza dos elementos que são evidenciados nessa nova forma de exercício de poder: fenômenos que fazem sentido apenas quando considerados no nível da massa e considerados em sua duração;

c) a passagem de mecanismos disciplinares para reguladores: fazemse previsões, criam-se estatísticas com o objetivo de intervir sobre as determinações dos fenômenos, não em mudanças no nível dos indivíduos, como baixar a morbidade, controlar taxa de natalidade. Para isso, tornam-se necessários mecanismos reguladores para atingir populações globais. De um modo geral, com essa tecnologia do biopoder, passa-se de um poder soberano absoluto de fazer morrer para um poder sobre a população, sobre a vida humana, um poder de "fazer viver", mas viver uma vida específica, normal.

Para Foucault (1999), o poder disciplinar sobre o corpo e o poder regulador sobre as populações são distintos, porém não excludentes. São duas tecnologias de poder sobrepostas e ambas se dirigem sobre o corpo, mas de maneiras diferentes:

Uma técnica que é, pois, disciplinar: é centrada no corpo, produz efeitos individualizantes, manipula o corpo como foco de forças que é preciso tomar úteis e dóceis ao mesmo tempo. E, de outro lado, temos urna tecnologia que, por sua vez, é centrada não no corpo, mas 
na vida; uma tecnologia que agrupa os efeitos de massas próprios de uma população, que procura controlar a série de eventos fortuitos que podem ocorrer numa massa viva; uma tecnologia que procura controlar (eventualmente modificar) a probabilidade desses eventos, em todo caso em compensar seus efeitos. É uma tecnologia que visa, portanto, não o treinamento individual, mas, pelo equilíbrio global, algo como uma homeostase: a segurança do conjunto em relação aos seus perigos internos. Logo, uma tecnologia de treinamento oposta a, ou distinta de, uma tecnologia de previdência; uma tecnologia disciplinar que se distingue de uma tecnologia previdenciária ou regulamentadora; uma tecnologia que é mesmo, em ambos os casos, tecnologia do corpo, mas, num caso, trata-se de urna tecnologia em que o corpo é individualizado como organismo dotado de capacidades e, no outro, de uma tecnologia em que os corpos são recolocados nos processos biológicos de conjunto (Foucault, 1999, p. 297).

Existem então duas séries, de acordo com Foucault (1999). A primeira, que trata do corpo organismos disciplina instituições. E uma segunda, que trata da população processos biológicos mecanismos reguladores Estado. A Medicina ocupa lugar privilegiado, pois, como nos mostra o autor em questão, essa disciplina pode ser considerada uma técnica política de intervenção e que produz efeitos de poder próprios; ao mesmo tempo, construção de saber e exercício de poder. Essa disciplina tem a capacidade de produzir, ao mesmo tempo, efeitos disciplinares e regulamentadores, pois se dirige tanto aos corpos individuais, aos organismos, quanto aos processos biológicos que incidem sobre a população de uma maneira global. Podemos perceber então que a Medicina ocupa lugar privilegiado em tempos de biopolítica, e essa consideração ultrapassa a obra de Foucault.

\section{A MEDICINA E A VIDA NUA}

Para o filósofo italiano Giorgio Agamben (2007), a biopolítica não surge a partir o final do século XVIII. A produção de um corpo biopolítico, para Agamben (2007), é o núcleo do poder soberano, portanto sempre esteve presente. A vida nua ou vida sacra é o conteúdo primeiro do poder soberano: "Soberana é a esfera na qual se pode matar sem cometer homicídio e sem celebrar um sacrifício, e sacra, isto é, matável e insacrificável, é a vida que foi capturada nesta esfera" (Agamben, 2007, p. 91). Para o autor, o elemento político originário seria justamente a vida nua, ou a vida exposta à morte, e esta esteve sempre presente.

$\mathrm{Na}$ biopolítica moderna, há uma violência sem precedentes à qual a vida está exposta. Para ilustrar um exemplo de homo sacer, ou de vida nua, o autor cita o caso do hebreu perante o nazismo. Ele afirma que os hebreus não foram vítimas de um louco e grande holocausto, mas foram mortos em uma dimensão 
possível pela biopolítica: apenas por estarem em uma condição de matabilidade. Agamben cita as palavras de Hitler, ao afirmar que eles foram mortos como "piolhos", ou como vida nua.

Um ponto característico da Modernidade, de acordo com Agamben (2007), é o fato de que o poder soberano sobre a vida nua não está mais nas mãos do soberano. $\mathrm{O}$ poder sobre a vida nua, caracterizado na Modernidade como o poder de atribuição de valor (ou desvalor) sobre as vidas, desloca-se para diversas áreas de saber. O poder soberano de decisão sobre a vida, agora sobre o valor da vida, passa do soberano para os juristas, cientistas, médicos:

No mesmo passo em que se afirma a biopolítica, assiste-se, de fato, a um deslocamento e a um alargamento, para além dos limites do estado de exceção, da decisão sobre a vida nua na qual consistia a soberania. Se, em todo Estado moderno, existe uma linha que assinala o ponto em que a decisão sobre a vida torna-se decisão sobre a morte, e a biopolítica pode deste modo converter-se em tanatopolítica, tal linha não mais se apresenta hoje como um confim fixo a dividir duas zonas claramente distintas; ela é, ao contrário, uma linha em movimento que se desloca para zonas sempre mais amplas da vida social, nas quais o soberano entra em simbiose cada vez mais íntima não só com o jurista, mas também com o médico, com o cientista, com o perito, com o sacerdote (Agamben, 2007, p. 128).

Para Agamben (2007), em cada sociedade, são definidas quem são as vidas nuas, as vidas indignas de serem vividas, e o autor acredita que as vidas consideradas vidas nuas têm aumentado a ponto que a vida nua não se encontra mais em lugares específicos ou em categorias definidas. Com o poder soberano sobre as vidas tendo se expandido para diversas áreas de saber, a decisão sobre o valor das vidas expande-se para cada vez mais zonas, chegando ao ponto em que a vida nua "habita o corpo biológico de cada ser vivente" (Agamben, 2007, p. 146). Dessa forma, de acordo com o autor, todos somos vidas nuas em potencial (vidas que podem ser consideradas destituídas de valor político), quando expostos ao conhecimento científico e às práticas vigentes na saúde.

De acordo com Agamben (2007), a estrutura da biopolítica moderna constituise na atribuição de valor sobre as vidas, e a característica central da biopolítica na modernidade é a integração da Medicina com a política. Nesse contexto, a Medicina ganha poder comparado ao poder soberano, pois os médicos passam a ter legitimidade para a tomada de decisões soberanas sobre valor e desvalor da vida: "Médicos e soberanos parecem trocar seus papéis." (Agamben, 2007, p. 150). Agamben (2007) afirma que, na Modernidade, o poder do soberano, antes de decidir quem poderá ser morto sem que fosse considerado homicídio, agora passa a ser o poder de decisão sobre quais vidas deixam de ser politicamente 
relevantes: "Na biopolítica moderna, soberano é aquele que decide sobre o valor ou sobre o desvalor da vida enquanto tal" (Agamben, 2007, p. 149).

A decisão sobre as vidas que valem a pena serem vividas aparece, por exemplo, no contexto hospitalar, onde essas decisões partem da equipe médica. Em estudo antropológico realizado por Moreira e Biehl (2005), na Unidade de Terapia Intensiva (UTI) de um hospital geral de alta tecnologia de uma cidade do Nordeste do Brasil, podemos perceber como a atribuição de valor sobre a vida dos pacientes definem as práticas a serem seguidas.

As condições de funcionamento da UTI caracterizam-se pela prevalência de tecnologia e pela disposição dos pacientes de forma em que possam ser constantemente monitorados: seja por procedimentos médicos, administração de medicamentos e alimentação, controle de monitores, respiradores, etc. De acordo com Moreira e Biehl (2005), essa forma de organização distancia o médico de uma visão integrada do paciente, e o foco das intervenções passa a ser o órgão ou sistema orgânico que deve ser tratado, conforme demonstra o relato de um dos profissionais médicos da UTI em questão:

Cada vez mais, com a monitorização, a gente olha o sistema do paciente, a gente se afasta um pouco da pessoa em si, a gente é obrigado a olhar mais os órgãos, a dividir o paciente em setores, e passa a olhar a pessoa como mais um setor. É difícil integrar tudo. A gente dá um plantão com o paciente grave, a gente fica ligado aos monitores, drogas aqui e ali, e não olha para o rosto do sujeito. Olha, examina a mucosa, mas não vê o rosto, vê a mucosa, mas não vê o fácies dele (Moreira \& Biehl, 2005, p. 23).

No contexto da UTI estudada por Moreira e Biehl (2005), os médicos definiam quais pacientes mereciam uma atenção especial, que era dada por uma disponibilidade maior de tempo por parte do médico para o seu tratamento, acesso aos equipamentos de maior tecnologia dentro da UTI, controle mais rigoroso do respirador e manutenção da intensidade dos procedimentos. Essas decisóes eram baseadas no prognóstico de cada paciente. O prognóstico, por sua vez, era baseado nas estatísticas e dados sobre determinada doença e também no feeling individual de cada profissional médico. Moreira e Biehl (2005) relatam que um exemplo disso é o fato relatado por um plantonista de que existiam na UTI apenas cinco respiradores Evita (mais sofisticados); dessa forma, pacientes considerados com menor prognóstico não tinham direito a esse respirador. Eles eram colocados em um respirador Bird (de tecnologia inferior), que, devido a uma menor interação aos parâmetros fisiológicos, limitavam a eficácia de uma recuperação respiratória do paciente. Essas decisões são baseadas no feeling dos profissionais e não necessariamente se apresentam como dados concretos 
a respeito do prognóstico do paciente ou, sequer, na decisão deste sobre estar nesse ambiente ou consumir as tecnologias nele localizadas. Um dos profissionais médicos entrevistados, ao falar sobre as decisões tomadas sobre quais pacientes disporão de um equipamento mais eficaz, relata que um paciente praticamente irrecuperável ficará com o Bird. Moreira e Biehl (2005) concluem:

Mesmo sem a certeza da inevitabilidade da morte, o limite de tolerância é estabelecido pelo grupo, ele existe, com variaçóes pessoais e de contexto. Percebemos que a máquina passa a representar a própria morte do paciente. A menor eficiência técnica da máquina é colocada à disposição do doente, significando a decisão de que este acabou de penetrar nos limites biológicos da morte, ou seja, não é mais necessário utilizarmos o Evita, o Bird já é suficiente (p. 24).

Outra prática médica baseada nos prognósticos, constatada por Moreira e Biehl (2005), era a informação passada na troca de plantôes de que o paciente é "SPE". Essa sigla significa "se parar, encene", e o que o médico quer dizer ao outro é que existe a possibilidade de o paciente morrer no plantão seguinte e, se isso acontecer, é preciso encenar uma reanimação. Essa encenação, que os autores afirmam ser algo como teatral, é necessária para resguardar os médicos diante de uma ação legal por parte da família, que pode vir a questionar os procedimentos utilizados com o familiar, e por parte dos profissionais não médicos. O relato de um dos profissionais, que parece não questionar ou refletir sobre essa prática, mostra a naturalidade com que essa encenação é realizada no contexto da UTI estudada:

A gente sabe que isso existe, mas é raramente questionado, é o que diz assim, esse paciente não tem mais o que fazer por ele, ninguém faz nada, e aí tem aquela coisa, o SPE, "se parar, encene", ninguém deixa o paciente morrer sem fazer uma reanimação qualquer. Que mesmo que não funcione, a gente tem o aspecto legal, a gente tem uma população imensa de, ela sabe disso (referindo-se à enfermeira que nesse momento entra na sala e sai em seguida), e é um pouco para se proteger delas, ninguém pode saber quem vai dizer o quê, então ninguém pode dizer que você não fez a massagem cardíaca, você fez. Fez para não funcionar, mas fez. Paciente com pouco prognóstico a gente sempre faz alguma coisa. A gente tem medo que a enfermeira, inimiga sua, ou auxiliar, diga, ah não [...]”. (Moreira \& Biehl, 2005, p. 25).

Ao mesmo tempo em que práticas de aceitação da morte, como a eutanásia, eram recusadas pelos profissionais médicos da instituição, práticas sutis de deixar morrer eram praticadas pelos médicos, sem que familiares fossem comunicados e sem protocolos formais a respeito do assunto. Essas práticas também não estão presentes no Código de Ética dessa categoria profissional. São práticas 
consideradas aceitáveis entre o grupo de profissionais médicos. Moreira e Biehl (2005) acreditam que praticar a eutanásia, por exemplo, constitui-se em uma ação positiva em relação a morte, enquanto que essas práticas de "não fazer" não carregam consigo um mesmo peso moral. Os autores afirmam, porém, que essa diferença é eticamente questionável.

$\mathrm{Na}$ atualidade, os hospitais representam uma cultura de tecnificação dos cuidados em saúde, pois baseiam suas práticas em uma assistência tecnologizada (Ferla, 2009), em tecnologias duras (Merhy, 2002). Merhy (2002) classifica as tecnologias envolvidas no trabalho em saúde como:

a) tecnologias duras (que se referem a máquinas e equipamentos),

b) tecnologias leves-duras (que se referem a saberes, a conhecimentos) e

c) tecnologias leves (que se referem a relações, a vínculos). Franco e Magalhães Júnior (2003) afirmam que, para um serviço produzir saúde, este deve basear seu trabalho nas tecnologias leves e leves-duras. Esse modelo de atenção em saúde que se baseia em tecnologias duras se refere ao modelo biomédico hegemônico, em que o cuidado é centrado na figura do médico, como representante do saber biomédico, e em procedimentos de alta tecnologia. Importante perceber que o modelo biomédico contribuiu para tornar a saúde um "mercado" lucrativo:

O "mercado" de saúde mobiliza uma parcela significativa do PIB dos países e o complexo produtivo que este mercado movimenta está entre os primeiros em termos de volume de recursos e empregabilidade. Essa particularidade está dada no âmbito do modelo biomédico vigente, uma vez que a racionalidade e a escala de poder hegemônicas constituem legitimidade para conceituar e operar práticas assistenciais e práticas discursivas sobre a saúde, sobre o corpo e sobre a doença e seus riscos, nem sempre mobilizadas pela melhora das condiçōes de saúde objetivas dos indivíduos e das coletividades (Ferla, 2009, p. 111).

Biehl e Eskerod (2007), em sua etnografia sobre o programa nacional da síndrome da imunodeficiência adquirida (AIDS), nos mostram outro exemplo de decisões médicas arbitrárias em relação à disponibilidade de tratamento. Biehl fez sua pesquisa de campo em Salvador, entre os anos de 1997 e 2005, junto a moradores de rua e pessoas em situação de extrema pobreza, todos vivendo com AIDS e, em determinado momento de sua história, vivendo no Caasah (instituição chamada de casa de apoio, que acolhia moradores de rua vivendo com a doença e mediavam o acesso aos tratamentos). Eskerod, fotógrafo profissional, retratou a singularidade dos pacientes com vírus da imunodeficiência humana (HIV). Um 
dos argumentos centrais da obra é que, no outro lado de uma política exemplar de acesso gratuito e universal ao tratamento, está uma nova economia política de farmacêuticos, que privilegia o acesso à medicação e não a prevenção e o cuidado, e que existe um importante paradoxo: ao mesmo tempo em que o País tornou a medicação disponível, não tornou disponível a infraestrutura necessária para o cuidado das populações. Biehl e Eskerod (2007) argumentam que essa intervenção médica resultou em tratamento efetivo para a classe trabalhadora e média, mas deixou de fora as pessoas marginalizadas, especialmente as que estão em situação de rua.

Biehl e Eskerod (2007) nos mostram que essa população necessita de subsídios para organização da própria vida, além do acesso à medicação, e que, desconsiderando outros fatores de assistência que se mostravam necessários, inclusive para a adesão ao tratamento medicamentoso, a equipe médica optava muitas vezes por não disponibilizar o tratamento para moradores de rua e usuários de drogas. Em entrevista com assistente social da unidade de AIDS de um hospital de Salvador, a profissional relata que eles não têm estrutura para ajudar esses pacientes e que os médicos não ajudam muito, pois se concentram apenas na doença e esquecem de "todo o resto". A profissional relata que apenas dois pacientes de rua comparecem regularmente para exames e que esses pacientes permanecem fora do sistema (os autores em questão afirmam que eles nem mesmo são contabilizados nas estatísticas). A assistente social do hospital relata então a verdade difícil de que existe um juízo de valor no qual os médicos, apesar da disponibilidade universal da medicação, decidem quais pacientes terão acesso a ela. Estes argumentam que não podem ter certeza de que os pacientes continuarão o tratamento, então é melhor não iniciá-lo, para que não seja criada uma resistência à medicação. Pacientes em situação de rua e os categorizados em determinados rótulos como de "drogadito" passam a ser excluídos desse "direito universal" de acesso ao tratamento.

\section{A MEDICALIZAÇÃO DA VIDA OU O “MERCADO DA SAÚDE MENTAL"}

Biehl (2008) realizou um estudo etnográfico em Porto Alegre, no período de 2000 a 2003, em uma instituição chamada Vita. Vita foi fundada no final da década de 80 do século passado, por um antigo usuário de drogas, como um centro de reabilitação para adictos de álcool ou outras drogas. O local se expandiu e cada vez mais passou a abrigar, além desses usuários, idosos, doentes mentais, pessoas vivendo com HIV/AIDS, etc. As pessoas eram deixadas ali, seja por familiares, hospitais, polícia, etc. Biehl (2008) constatou que as pessoas 
ali esperavam "com a morte", pois se encontravam em situação de extremo abandono, recebendo alimentação mínima para sobreviver e onde os cuidados se resumiam em sedativos. Ele constatou que as pessoas ali se transformavam em ruínas.

Infelizmente instituições como a Vita não são exceção. Apenas em Porto Alegre, existem mais de 200 instituições semelhantes que funcionam muitas vezes clandestinamente, e a maioria delas são chamadas de "casas geriátricas". Biehl (2008) nomeia Vita como uma zona de abandono, pois ali são "hospedados" abandonados de todas as idades e que não vêm apenas da camada mais pobre da população. Muitos residentes da instituição vieram da classe média e classe trabalhadora, tendo tido famílias e as sustentado.

$\mathrm{Na}$ instituição Biehl (2008) conheceu Catarina, que era considerada pela família um experimento médico que não deu certo. Catarina havia passado por diversos hospitais psiquiátricos e postos de saúde. Ao investigar a sua história, por meio dos seus relatos e também por contato com parentes, ex-marido, filhos e instituiçôes, o antropólogo percebeu a forma como famílias livram-se de membros indesejados. O autor afirma que existe uma avaliação e decisão por parte das famílias sobre quais vidas merecem continuar e quais não.

Biehl (2008) procura mostrar a forma como processos médicos afetam o curso da vida nos espaços urbanos. Em parte do seu texto, que chama de "Experimentalismo farmacológico", o autor nos mostra que, nas diversas instituições em que passou, os diagnósticos dados pelos psiquiatras variavam de esquizofrenia até psicose pós-parto, anorexia e anemia. Outros diagnósticos encontrados para Catarina foram psicoses não determinadas e desordens de humor. $\mathrm{O}$ antropólogo constatou que o caso de Catarina não era exceção, e que a sua história não era considerada nesses diagnósticos. Essa falta de critérios ao estabelecer diagnósticos e essa inconsequência que acompanha muitos serviços psiquiátricos parecem estar mais presentes nos serviços que trabalham com classes populares:

A psiquiatria local, presa entre a política de desinstitucionalização, a escassez de verba pública e a proliferação de novas classificaçōes e tratamentos, não conseguiu lidar com sua particularidade nem com sua condição social. Ou seja, ela foi submetida ao típico e duvidoso tratamento reservado aos pobres das cidades. Clínicos receitavam remédios no escuro, sem dar atenção à sua condição distinta. Como muitos outros pacientes, Catarina era considerada agressiva e, por isso mesmo, sedavam-na em demasia, de modo que a instituição continuava a funcionar sem fornecer tratamento adequado (Biehl, 2008, p. 433).

Catarina, com as tendências psiquiátricas se modificando, foi tendo seus diagnósticos suavizados com o tempo, porém ela continuava sendo medicada 
com antipsicóticos pesados e várias drogas para tratamento dos efeitos colaterais destes. Sintomas relacionados à dose excessiva de medicação estavam presentes também nos achados de Biehl (2008), por exemplo, a hipotensão. O autor demonstra sua surpresa ao constatar a forma com que os psiquiatras lidavam com a questão da medicação e com o tratamento. Ele afirma que, ao ler os prontuários de Catarina, não era possível estabelecer uma diferenciação entre o que seriam os sintomas psiquiátricos e o que seriam os efeitos das medicaçóes, e que os médicos não pareciam preocuparem-se com isso. No caso de Catarina e das experimentações farmacológicas que nela eram testadas, os efeitos das medicações confundiam-se com seu próprio ser, a ponto de a paciente, em um de seus "dicionários", mudar seu nome para "Catkine", em referência à droga psiquiátrica "Akineton":

Esses bens farmacêuticos - que às vezes funcionam como rituais - convertem-se em espíritos imaginários em vez de verdades materiais, concretas, que supostamente representam: mercadorias tornam-se então sujeitos. Há uma ciência de fazer dinheiro na moléstia de Catarina (Biehl, 2008, p. 435).

Biehl (2008) conta um episódio em que Catarina foi hospitalizada e medicada com antipsicóticos sem critério algum e, quando recebeu alta, o médico explicou para uma parente como cuidar dela: "O doutor explicou como lidar com ela. Disse para a gente dar uma dose e, se não melhorasse, simplesmente ir dobrando as doses" (p. 437).

Poderíamos pensar em Catarina como uma vida nua, de acordo com o conceito proposto por Agamben (2007), uma vida considerada destituída de valor pelos profissionais médicos e, dessa forma, qualquer tratamento dado a ela é considerado suficiente, mesmo que claramente o tratamento dispensado seja ineficaz e até mesmo prejudicial. Porém, no contexto citado, Biehl não se contenta com a simples categorização de Catarina como uma "vida nua". Biehl (2008) afirma, inclusive, que fica feliz de a ter conhecido antes de ler a obra "Homo Sacer", de Agamben, considerando que essa obra, escrita com base no trabalho de Michel Foucault sobre o biopoder, apresenta uma visão desumanizada, melancólica e até mesmo comovente e afirma: "Uma forma de vida humana que não vale a pena viver não é apenas matéria bruta. A linguagem e o desejo continuam" (p. 441). Biehl (2008) afirma que, mesmo que Catarina tivesse sido submetida a tratamentos ineficazes e prejudiciais, e estivesse vivendo em uma situação de abandono, a vida e o desejo continuavam presentes nela.

O estudo com Catarina mostrou como práticas de medicalização indiscriminada ultrapassaram barreiras de clínicas e hospitais para dentro das casas. Para Biehl, remédios fortíssimos, como antipsicóticos, tornaram-se tão 
comuns como o Buscopan. No caso de Catarina, a utilização dessas drogas provocaram efeitos mentais e físicos, que a transformaram em um "experimento mortal" (Biehl, 2008, p. 413). Um ponto importante levantado por Biehl (2008) é como a medicalização da vida expandiu-se do domínio médico e tornou-se parte importante da vida familiar:

A família é uma espécie de agente médico do Estado, uma vez que ela faz a triagem dos cuidados e do tratamento. A distribuição gratuita de medicamentos (que inclui psicotrópicos) é, de fato, um componente importante das iniciativas que visam um sistema universal de saúde mais eficiente e econômico. Mas é também o vetor de uma crescente farmacolização da saúde pública em detrimento de outras iniciativas preventivas e de infraestrutura. Produtos farmacêuticos tornaram-se uma ferramenta fundamental nas deliberaçôes sobre quem vive e a que custo vive. Ao se engajar com esses novos regimes de saúde pública e ao alocar seus já esticados e escassos recursos, famílias aprendem a agir como "proxy-psychiatrists", ou psiquiatras de fundo de quintal, podendo se livrar de seus membros improdutivos e indesejados, às vezes sem sanção, baseados no fato de que tais indivíduos não se submetem aos regimes de tratamento. Psicotrópicos mediam o abandono, tanto pelo valor de verdade científica que conferem ao que está acontecendo como também pelas alteraçôes químicas que ocasionam. Essas drogas, que acabam funcionando como tecnologias morais, na realidade fazem com que as perdas de laços sociais sejam irreversíveis (Biehl, 2008, p. 440).

Sobre a situação atual da atenção à saúde mental no Brasil, Biehl (2008) afirma que a reforma psiquiátrica veio acompanhada de incremento progressivamente maior nogasto com medicamentos psicoativos, mesmo com a redução proporcional do número de profissionais que utilizam predominantemente medicamentos na sua abordagem assistencial, e nos mostra um quadro inquietante:

Em 1995, por exemplo, as internaçōes psiquiátricas representavam $95,5 \%$ do total de gastos com saúde mental, passando para 49,3\% em 2005. No mesmo período, houve um aumento significativo nas despesas com serviços comunitários e medicação. A distribuição de psicotrópicos cresceu de 0,1\% em 1995 para 15,5\% em 2005. 75\% dos gastos com medicamentos neste período foram com novas drogas antipsicóticas (Biehl, 2008, p. 417).

Biehl (2008) questiona-se sobre as possíveis formas de pensar e viver que surgiram a partir do que chama de "farmacolização" da saúde mental, que, de acordo com o autor, está a serviço de "uma forma difusa de governança e expansão de mercado" (p. 417). Quem sofre especialmente com isso é a população de baixa renda no Brasil, pois o uso de novas tecnologias médicas e medicalização excessiva nos contextos urbanos de baixa renda se mostra muito presente. Essa forma de "cuidado" em saúde, que se caracteriza por um tratamento predominantemente medicamentoso, muitas vezes de forma indiscriminada, é um desafio para a integralidade em saúde. 
A medicalização da vida está tomando dimensões alarmantes. O caso de Catarina é apenas um exemplo de uma vida vítima do poder do discurso e da tecnologia médica. Muitas outras vidas percorrerão o mesmo caminho de Catarina, se depender da Associação Americana de Psiquiatria (APA). A APA está propondo uma ampliação das doenças psiquiátricas categorizadas no Manual Diagnóstico e Estatístico de Transtornos Mentais, que está em sua quarta edição (DSM IV). Paulo Amarante, diretor do Centro Brasileiro de Estudos de Saúde (Cebes), e Fernando Freitas, ambos pesquisadores do LAPS/Fiocruz, escreveram um texto sobre o novo Manual Diagnóstico e Estatístico de Transtornos Mentais (DSM V), presente no blog do Cebes (Freitas \& Amarante, 2012). Nesse texto, os pesquisadores argumentam que o DSM representa a medicalização crescente do nosso cotidiano e nos mostram a dimensão da "inflação" dos objetos da psiquiatria. Eles afirmam que, há 50 anos, eram apenas seis as categorias de diagnóstico psiquiátrico; hoje são mais de 300. Os pesquisadores argumentam que os impactos a partir de cada edição são inúmeros e que, curiosamente, as pesquisas para que novos distúrbios sejam descobertos e categorizados são financiados, além de outras fontes, por grandes conglomerados da indústria farmacêutica, como a Ortho-McNeil Pharmaceutical, a GlaxoSmithKline, Bristol-Eyers Squibb e Shire. Freitas e Amarante (2012) afirmam:

O DSM-V reforça a tendência a assegurar e a ampliar o mercado da saúde mental: 1) o consumo arbitrário de medicamentos de natureza psicotrópica, sem qualquer cuidado com os seus efeitos sobre a própria saúde de seus consumidores; (2) a expansão de serviços de diagnóstico e de consultas; (3) a medicalização da vida. Na medida em que o modelo "a-teórico" (como ele mesmo se define) do DSM nos possibilita constatar, principalmente a partir desta sua quinta versão, que seu objetivo real não é lançar luz sobre o conhecimento dos sofrimentos mentais, e sim produzir mais mercado para as intervenções psiquiátricas.

Um vetor de forças em direção à medicalização da vida está fortemente presente na atuação dessas organizações, e é preciso o pensamento ativo para resistir ao discurso que objetualiza a vida na doença e na utilidade dos corpos.

\section{CONSIDERAÇÕES FINAIS}

Um cuidado que pretenda produzir saúde para a população no nosso contexto precisa ter como meta a integralidade em saúde. Esta depende de um trabalho interdisciplinar que considere os diversos contextos socioculturais dos que demandam cuidado e tenha em seu núcleo o trabalho vivo, ou seja, as relaçóes e o vínculo entre profissionais e usuários/pacientes. Porém o modelo de atenção à saúde ainda vigente é um modelo centrado na figura do médico, como profissional central na lógica vigente, na doença como foco das intervenções, no consumo de 
procedimentos de alta tecnologia e no uso excessivo de medicamentos, ou seja, no modelo biomédico hegemônico. Apesar de esse modelo estar sendo questionado, existem muitos desafios para que mudanças reais nos serviços aconteçam.

A partir das contribuiçôes de Michel Foucault sobre o surgimento da biopolítica, podemos entender como a Medicina se tornou política da vida e como se transformou em ferramenta para o controle da população pelo Estado. $\mathrm{O}$ autor nos alerta que, em tempos de biopolítica, em que a vida passa a ser alvo de controle pelo Estado em seus diferentes arranjos, a Medicina ocupa lugar privilegiado, pois essa disciplina pode ser considerada uma técnica política de intervenção e que produz efeitos de poder próprios. Essa disciplina tem a capacidade de produzir, ao mesmo tempo, efeitos disciplinares e regulamentadores, pois se dirige tanto a corpos individuais, a organismos quanto a processos biológicos que incidem sobre a população de uma maneira global. Evidente que esse não é o único vetor de forças que se projeta sobre a produção individual e coletiva da saúde: outros discursos também operam e, sobretudo, há fraturas importantes e cada vez mais visíveis nesse modelo. $\mathrm{Na}$ coadjuvância com as diferentes forças, suportadas em diferentes discursos sobra a saúde e a doença, rearranjam-se as forças de resistência e também o discurso biomédico.

O filósofo italiano Giorgio Agamben nos mostra que o poder soberano de fazer morrer na atualidade caracteriza-se por um poder de decidir sobre o valor das vidas. Nesse contexto, o poder soberano parte de diversas áreas, entre elas a Medicina, ao ponto de, segundo o autor, os médicos e soberanos parecerem trocar seus papéis. Exemplos do poder médico soberano podem ser constatados, por exemplo, na obra de João Biehl, tanto na área hospitalar quanto na área da saúde mental, em que as decisões médicas afetam o curso das vidas que estão, de certa forma, em suas mãos.

A medicalização da vida cotidiana se constitui como exemplo de como o poder médico unido a lógicas e interesses de mercado podem afetar, de forma dramática, a sociedade, em especial em contextos urbanos pobres, ou aos amplos segmentos da sociedade que têm migrado da zona de pobreza para um extrato social e cuja migração nem sempre é acompanhada de consolidação de tecidos de sustentação cultural e política e, portanto, permanecem suscetíveis à lógica de valores que procurava constitui-los na condição anterior.

De um modo geral, as reflexões com base na área da Filosofia e da Antropologia se articulam às contribuiçôes de importantes autores da saúde coletiva e nos permitem entender como o "terreno se tornou fértil" para que o poder médico pudesse germinar e tomar dimensões exorbitantes, e como o exercício desse saber-poder afeta, dentro dos serviços de saúde, a vida das pessoas de carne e osso. 
Também nos permitem perceber como o cuidado em conexão com os diferentes aspectos da vida das pessoas, organizado com base em tecnologias relacionais, pode fortalecer vetores de resistência à lógica biomédica e sua articulação com os interesses do capitalismo contemporâneo. O debate em torno da ideia-força da integralidade e da dimensão micropolítica do cuidado, conforme aponta Emerson Merhy, tem se mostrado potente para isso. Mais do que mostrar um caminho, esse ensaio pretendeu mobilizar o pensamento, de um lado para os arranjos novos e clássicos da biomedicalização da vida, conforme nos apontam Foucault e Agamben, por outro apontar brechas e a necessidade de novos conhecimentos e práticas para o cuidado em saúde. A aposta na vida que pulsa no cotidiano dos serviços de saúde e do ir e vir das pessoas requerer novas capacidades profissionais e é preciso deixar fluir ideias e ações que quebrem o lugar das divindades no discurso sobre a saúde e constituam lugares no cotidiano, no qual, afinal, a saúde se produz, é perdida e é novamente retomada, num ciclo que é a própria vida. 


\section{REFERÊNCIAS}

Agamben, G. (2007). Homo Sacer: o poder soberano e a vida nua. H. Burigo (Trad.). Belo Horizonte: Editora UFMG.

Biehl, J. G. (2008). Antropologia do devir: psicofármacos - abandono social desejo. Revista de Antropologia, 51(2), 413-449. Recuperado a partir de http:// www.revistas.usp.br/ra/article/view/27285/29057

Biehl, J. G. \& Eskerod, T. (2007). Will to live: AIDS therapies and the politics of survival. Princeton: Princeton University Press.

Ferla, A. A. (Coord.).(2009). Saúde suplementar nas Regióes Norte e Sul: estudos multicêntricos integrados sobre modelagem assistencial e integralidade do cuidado. (Relatório de Pesquisa), Universidade Federal do Rio Grande do Sul, Escola de Enfermagem, Graduação em Análise de Sistemas e Serviços de Saúde, Bacharelado em Saúde Coletiva, Porto Alegre.

Freitas, F. \& Amarante, P. (2012). Psiquiatrização da vida e o DSM V: desafios para o início do século XXI. Centro Brasileiro de Estudo de Saúde (CEBES). Recuperado a partir de http://cebes.org.br/2012/03/psiquiatrizacao-da-vidae-o-dsm-v-desafios-para-o-inicio-do-seculo-xxi/

Foucault, M. (1999). Em defesa da sociedade: curso no Collège de France (19751976). M. E. Galvão (Trad.). São Paulo: Martins Fontes.

Franco, T. B. \& Magalhães Júnior, H. M. (2003). Integralidade na assistência à saúde: a organização das linhas do cuidado. In E. E. Merhy, H. M. Magalhães Júnior, J. Rimoli, T. B. Franco \& W. B. Silva (Orgs.), O trabalho em saúde: olhando e experienciando o SUS no cotidiano. (pp. 125-132). São Paulo: Hucitec.

Franco, T. B. \& Merhy, E. E. (2007). Programa de Saúde da Família (PSF): contradições de um programa destinadoà mudança do modelo tecnoassistencial. In E. E. Merhy, H. M. Magalhães Júnior, J. Rimoli, T. B. Franco \& W. B. Silva (Orgs.), O trabalho em saúde: olhando e experienciando o SUS no cotidiano. (pp. 55-124). São Paulo: Hucitec.

Merhy, E. E. (2002). Saúde: a cartografia do trabalho vivo em ato. São Paulo: Hucitec.

Merhy, E. E. \& Franco, T. B. (2003). Por uma composição técnica do trabalho centrada nas tecnologias leves e no campo relacional. Saúde em Debate, 27(65). Recuperado a partir de http://www.professores.uff.br/tuliofranco/textos/ composicao_tecnica_do_trabalho_emerson_merhy_tulio_franco.pdf. 
Moreira, E. C. \& Biehl, J. (2005). Práticas médicas de aceitação da morte na UTI de um hospital geral no Nordeste do Brasil. Revista Bioética, 12(1), 19-30.

Spink, M. (2010). Psicologia Social e Saúde: trabalhando com a complexidade. Quaderns de Psicologia, 12(1), 41-56. Recuperado a partir de http://www. quadernsdepsicologia.cat/article/viewArticle/752 